\title{
An overview of clinically and healthcare related apps in Google and Apple app stores: connecting patients, drugs, and clinicians
}

\author{
Samuel Ken-En Gan ${ }^{1,2^{*}}$, Cornelius Koshy ${ }^{1}$, Phi-Vu Nguyen ${ }^{1}$ and Yu-Xuan Haw ${ }^{1}$
}

\begin{abstract}
Successful clinical outcomes involve both clinician and patient factors such as good decision making, accurate diagnosis, patient compliance, effective monitoring of the condition, and accurate interpretation of clinical results. With a general trend in healthcare towards personalized medicine, the smartphone holds great potential to play a role in personalized care and aid in the above mentioned factors. Through the use of apps, the increasingly powerful smartphone may be a useful aid in the healthcare and clinical industries. This review surveys the currently available apps in Google and Apple app stores that are purposed for aiding healthcare and clinical use, and discusses how they may also help transform the smartphone in a medically relevant device.
\end{abstract}

\section{Introduction}

In ancient times, physicians made house visits to the sick, often administering medical attention within the comforts of the patient's home. Although house-visits do continue to exist today, they are more common in smaller towns or village communities and the very affluent in cities. In the developed world, there is a trend of reversal in the mode of medical care of our forefathers: from doctors attending to patients in their homes, to patients consulting doctors in hospitals.

Such changes have risen out of the necessity for efficiency and improved healthcare. In a hospital/clinic, the concentration of medical expertise, equipment and sanitized environment improves the quality of healthcare over house-visits. Nonetheless, both models of consultation have their own disadvantages. In house visits, the physician's travelling time slows down the immediacy of care and compromises diagnostic accuracy without the necessary medical equipment (e.g. X-Ray machine). On the other hand, we have the very real problem of long

\footnotetext{
* Correspondence: samuelg@bii.a-star.edu.sg

'Bioinformatics Institute, Agency for Science, Technology, and Research (A*STAR), Singapore 138671, Singapore

${ }^{2}$ p53 Laboratory, Agency for Science, Technology, and Research (A*STAR), Singapore 138648, Singapore
}

patient waiting hours just for a few minutes of consultation or the collection of test results.

Regardless of the consultation model, today's world offers a solution which overcomes the flaws of each model: the smartphone. With the advancement and incorporation of technology into healthcare, it might be possible to do away with physical visits, especially with video or other imaging technology through smartphones. Patients can get a quick consultation or access their test results with accompanying clinical comments easily. If advanced equipment are required, there might be possibility to leverage on smartphone sensors as simple medical equipment (e.g. microphone as a stethoscope), turning the smartphone into a multi-purpose mobile medical equipment that can be used by both patients and clincians.

Nonetheless, when dealing with clinical procedures, accuracy and precision outweighs convenience and time. With the growth of technology in medical diagnostics (e.g. electronic ECG, electronic X-Ray), accuracy and efficiency are not necessarily mutually exclusive. Thus, there is potential for the use of apps and wirelessly connected peripheral added sensors to enable the smartphone to change the workings of the healthcare industry.

In spite of this potential and the pockets of activity towards this cause, there is a dearth of literature covering 
Table 1 Clinical apps classified in 'communication' (as of Jan 2016)

\begin{tabular}{|c|c|c|c|c|}
\hline App name & OS & Description & App type & Hardware \\
\hline DrBridge & Android & $\begin{array}{l}\text { Helps doctors to follow up with patients and deliver care plans through } \\
\text { text messaging, email and app-to-app interactions }\end{array}$ & Hybrid & None \\
\hline Drchrono EHR/EMR & iOS & Allows doctors to communicate with their patients & Hybrid & None \\
\hline GatherPro & Android & Allows doctors to communicate with their patients & Hybrid & None \\
\hline - Patient Portal by ConstantMD & & Allows doctors to communicate with their patients & & \\
\hline HealthJump & iOS & Communicates with doctors to schedule appointments & Hybrid & None \\
\hline Medical \& Health Records Caddy & Android \& iOS & $\begin{array}{l}\text { Manages and share patient list as well as patient tasks, notes, medications, } \\
\text { records, images, and messages. }\end{array}$ & Hybrid & None \\
\hline Message patient management & iOS & Organises patient and treatment sessions & Hybrid & None \\
\hline MedBooking & iOS & Allows patients to book their appointments & Hybrid & None \\
\hline Practo Ray & iOS & Calls Patients for appointments & Hybrid & None \\
\hline SirenMD & iOs & Sends messages, medical records and photos between health professionals & Hybrid & None \\
\hline
\end{tabular}

the already available clinical aid apps that both the patient and the clinician can leverage on. To address this, this review discusses the currently available clinically and medically relevant apps and how they might be incorporated into practice for better outcomes.

\section{The future of mobile apps}

Efficiency is one of pursuits of excellent healthcare especially in today's growing demands of ageing populations in many developed societies. Incorporating mobile apps with internet connectivity into routine medical processes (e.g. consultations) enhances the convenience for both doctors and patients alike. In the common problem of long waiting times, registration and appointments can be booked using mobile apps without long queues for the receptionist. Similarly, medical results or clinically relevant pictures taken by patients can be sent through secured apps to physicians and specialists for consultations without the physical transfer of document between hospital departments. With increased efficiency in consultations and diagnosis, patients can be treated earlier, thereby improving prognosis. It might even be possible to do away with face to face outpatient consultations or routine follow-up through the use of apps. Patients can

Table 2 Clinical apps classified in 'patient data management' (as of Jan 2016)

\begin{tabular}{|c|c|c|c|c|}
\hline App name & OS & Description & App type & Hardware \\
\hline Clinic On Go - My Patients & Android & Manages patient information and appointments & Hybrid & None \\
\hline $\begin{array}{l}\text { Doctors Aid - OPD Management } \\
\text { - Doctor Assist } \\
\text { - Doctor Assistant } \\
\text { - My patients } \\
\text { - Patient Doctor Records }\end{array}$ & Android & Manages and stores patients' health and medical records & Native & None \\
\hline $\begin{array}{l}\text { Doctor Buddy - Patients Manager } \\
\text { HouseOfficer } \\
\text { Lybrate For Doctors }\end{array}$ & iOS & $\begin{array}{l}\text { Manages and stores patient info for Doctors } \\
\text { Manages and store patient info for Doctors } \\
\text { Manages and store patient info for Doctors }\end{array}$ & Native & None \\
\hline Hospital Rounds Management & iOS & Stores patient details, diagnosis and billing codes & Native & None \\
\hline iGrade for psych & iOS & Manages patient info for psychotherapists & Native & None \\
\hline MDclick for Physicians & iOS & Shares patient info with other health professionals & Hybrid & None \\
\hline MedicosA & Android & $\begin{array}{l}\text { Enables Physicians to access patient appointments, patient history, } \\
\text { and write e-prescriptions }\end{array}$ & Hybrid & None \\
\hline OPD MANAGEMENT & Android & $\begin{array}{l}\text { Stores information such as Patient History, Patient Diagnosis, } \\
\text { and Prescription }\end{array}$ & Native & None \\
\hline Patient History Taker & Android & Database app for medical history for patients & Native & None \\
\hline Practice Management & Android & An application that helps record data of patient & Hybrid & None \\
\hline Patient Management System & Android & $\begin{array}{l}\text { Manages the patient's medical record and able to standardize } \\
\text { diagnosis and action. }\end{array}$ & Native & None \\
\hline Patient List & iOS & Keeps track on patients' info & Hybrid & None \\
\hline Prescapp - Doctors & $\mathrm{iOS}$ & Manages and stores patient info & Native & None \\
\hline
\end{tabular}


receive professional consultation through apps in the comfort of their homes, a scenario that is especially beneficial for elderly patients or those with high dependency to getting around.

\section{Displacing medical equipment for lower healthcare costs}

The rising costs of healthcare, contributed by the increasing costs of skilled personnel, medical equipment and infrastructure, poses a challenge to accessible healthcare to the less privileged in society. On this problem, the smartphone might help to reduce costs by displacing expensive medical equipment with clinical mobile apps that leverage on the many sensors in smartphones. One such example is the displacement of a heart rate monitor (costing between USD\$70 - \$150) with a free heart rate monitor app that functions via the in-built microphone or camera. Coupled with internet connectivity, one can even easily send results to clinicians, a feature that most current medical equipment lack. Should artificial intelligence be incorporated, these apps may further aid in diagnosis by detecting abnormalities.

\section{Patient compliance}

Patient compliance to clinical advice and care is essential for successful clinical outcomes (Martin et al. 2005). The most effective treatment regimens would be rendered ineffective if patients failed to comply. This is particularly true for chronic diseases where patient compliance directly affects disease control. On this aspect, mobile apps that monitor patient conditions and sends reminders of treatment would certainly be a boon for chronic disease management. This is especially so if clinicians can use such apps to monitor disease/symptoms for diagnosis and adjustment of treatment methods.

\section{Clinical mobile apps}

In view of the potential for mobile apps in the abovementioned areas, we did a survey of apps in the Google and Apple app stores using key words: "patient info management", "patient health monitor", "eye diagnosis", "skin diagnosis", "blood pressure", "heart beat rate", "medical calculator" and "patient compliance". As of early 2016, we found over 1121 and 536 apps in Google Play Store and Apple App Store, respectively. Only about 139 apps of these were directly relevant to practical uses for healthcare. Of these, 30 apps were for patient data management and communication; 44 apps for patient health monitoring; 36 apps for clinical diagnosis; 21 apps for medical calculations; and 7 apps for patient compliance. Within these, we further classified them into nine categories based on their functions.
Table 3 Clinical apps classified in 'patient health monitors and trackers' (general health) (as of Jan 2016)

\begin{tabular}{lllll}
\hline App name & OS & Description & $\begin{array}{l}\text { App } \\
\text { type }\end{array}$ & Hardware \\
\hline Cure companion & Android & $\begin{array}{l}\text { Keeps track of patients' } \\
\text { health records }\end{array}$ & Hybrid & None \\
$\begin{array}{l}\text { Data Manager } \\
\text { for Fitbit }\end{array}$ & iOS & $\begin{array}{l}\text { Track health related data } \\
\text { such as weight, sleep and } \\
\text { body fat }\end{array}$ & Native None & \\
HealthTouch & iOS & $\begin{array}{l}\text { Records and tracks key } \\
\text { health stats } \\
\text { Monitors the body } \\
\text { temperature }\end{array}$ & Native None & Native None \\
iThermonitor & iOS & & & \\
\hline
\end{tabular}

The various categories of apps relevant to healthcare and medical purposes

Clinical care communication [Table 1]

In healthcare, timely communication between a patient and doctor enables the former to get medical advice and the latter to keep track of the patient condition and intervene when necessary. A range of clinical communication apps have been developed to facilitate better communication between patients and clinicians. One notable example of such apps is 'HealthJump' (Healthjump Inc 2015) which not only allows patients to schedule their appointments with their doctors, but also provides medical records securely.

\section{Patient data management [Table 2]}

Patient data management is tantamount for accurate diagnosis/disease management and has to be secured to ensure patient confidentiality. Incomplete or missing reports can result in the loss of crucial information that could have serious clinical consequences (e.g. drug allergies). Apps in this area facilitate the viewing, storage and management of patient data without the spatial constraints of desk-bound medical computer systems. 'My Patients' (Evgeny 2015) and 'Patient Reports Doctor ON GO-T’ (Siyami Apps 2015) are example apps that allow the clinicians to view patients' medical history, diagnosis and prescription on the go. Such apps make clinical rounds in the ward or house visits much more convenient, doing away with bulky files and folders.

Table 4 Clinical apps classified in 'patient health monitors and trackers' (heart rate) (as of Jan 2016)

\begin{tabular}{lllll}
\hline App Name & OS & Description & App type & Hardware \\
\hline Cardiograph pro & Android & $\begin{array}{l}\text { Saves patient's daily } \\
\text { Blood Pressure and } \\
\text { Heart Rate }\end{array}$ & Native & None \\
Heart Rate monitor iOS & $\begin{array}{l}\text { Tracks and records } \\
\text { heart rate }\end{array}$ & Native & None \\
PulsePRO & iOS & $\begin{array}{l}\text { Monitors patient } \\
\text { heart rate }\end{array}$ & Hybrid & None \\
\hline
\end{tabular}


Table 5 Clinical apps classified in 'patient health monitors and tracker' (blood pressure) (as of Jan 2016)

\begin{tabular}{|c|c|c|c|c|}
\hline App Name & OS & Description & App type & Hardware \\
\hline Acc. Blood pressure & Android & Keeps track on blood pressure measurements & Native & None \\
\hline Best Blood Pressure Monitor & iOS & $\begin{array}{l}\text { Tracks and automatically collect blood pressure measurements } \\
\text { via bluetooth }\end{array}$ & Native & Tonometer \\
\hline Blood Pressure & iOS & Manages and track blood pressure progress & Native & None \\
\hline Blood Pressure (BP) Watch & Android & Collect, track, analyze and share your blood pressure record & Native & None \\
\hline Blood Pressure Companion & iOS & Tracks Blood pressure, weight and heart health & Native & None \\
\hline Blood pressure diary & Android & Keeps track on blood pressure records & Native & None \\
\hline Blood pressure monitor pro & Android \& iOS & Keeps track on blood pressure records & Native & None \\
\hline Blood Pressure log diary & Android & Keeps track on blood pressure records & Native & None \\
\hline Blood Pressure Tracker & Android & Tracker of Patients' blood pressure records & Hybrid & None \\
\hline Blood Pressure PRO & Android & Collect and analyze blood pressure measurements & Native & None \\
\hline Blood Pressure lite & Android \& iOS & helps keep track of blood pressure and weight & Native & None \\
\hline Blood Pressure + Pulse Grapher lite & iOS & Records blood pressure and pulse rate measurements & Native & None \\
\hline Bloody Pressure & iOS & Record, track and share blood pressure measurements. & Native & None \\
\hline HeartStar Blood Pressure Monitor & iOS & Monitors blood pressure and automatically records via bluetooth & Native & none \\
\hline My Blood Pressure & Android & Records blood pressure measurements taken & Native & None \\
\hline
\end{tabular}

Besides secured data transmission and data encryption necessary for patient confidentiality, there are other limitations for such apps. One such limitation is the accessibility of file formats where certain medical equipment may store data (e.g. X-Ray, ECG printouts etc.) in specific file formats not easily accessed on the apps. It is also questionable if the small screen of these mobile devices would allow sufficient analysis of important test results (e.g. small abnormalities in $\mathrm{X}$-Rays). Although difficult viewing conditions may increase human errors, this can be mitigated with image processing algorithms that perform automated diagnostic parameters to detect anomalies.

Patient health monitors and trackers [Tables 3, 4, 5, 6, 7, 8, 9, 10 and 11]

Apps in this category facilitate the recording and monitoring of disease conditions after diagnosis. In the example of hypertension, ambulatory monitoring may enable better diagnosis (Gan et al. 2003) as compared to readings taken at clinics that may be confounded by psychosomatic fear. Some apps in this category can do more to make a comparison analysis with previous data and

Table 6 Clinical apps classified in 'patient health monitors and trackers' (skin conditions) (as of Jan 2016)

\begin{tabular}{lllll}
\hline App name & OS & Description & $\begin{array}{l}\text { App } \\
\text { type }\end{array}$ & Hardware \\
\hline FotoSkin & $\begin{array}{l}\text { Android } \\
\text { \& iOS }\end{array}$ & $\begin{array}{l}\text { Tracks photos of patient's skin } \\
\text { for easy diagnosis of skin } \\
\text { cancer for dermatologist. }\end{array}$ & Hybrid & Camera \\
Skin Tagger iOS & Tracks photos of skin pictures & Hybrid & Camera \\
\hline
\end{tabular}

alert the user of significant fluctuations in the condition. 'Blood Pressure Diary' (FRUCT 2016) and 'PulsePRO' (Cocoalena Software 2015) are examples of such apps that record, analyse and send the clinical measurements to attending physicians without the need of an ambulatory machine (typically costing up to hundreds of dollars). With a wide range of types and functions, other apps are also made to track patient's general health, skin problems, eye problems, blood parameters, menstrual cycles and the presence of diseases. With such monitors and trackers, behavioural changes that improve eating habits and physical activity levels have been observed in young adults. Thus such monitoring apps do encourage patients to be more aware of their daily condition (Higgins 2015).

\section{Heart rate measurement [Table 12]}

As a subgroup of the health monitoring apps, heart rate measurement apps form a significant bulk of the group in the mega app stores. Basic heart rate information can be an indicator of general health and aid in both monitoring and detection of cardiac problems. Apps in this category often function like a stethoscope by using the microphone or camera in the smartphones.

Table 7 Clinical apps classified in 'patient health monitors and trackers' (eye conditions) (as of Jan 2016)

\begin{tabular}{|c|c|c|c|c|}
\hline App name & OS & Description & $\begin{array}{l}\text { App } \\
\text { type }\end{array}$ & Hardware \\
\hline $\begin{array}{l}\text { Paxos } \\
\text { checkup }\end{array}$ & iOS & $\begin{array}{l}\text { Allows patients to monitor their } \\
\text { vision and physicians to keep track }\end{array}$ & Hybrid & None \\
\hline
\end{tabular}


Table 8 Clinical apps classified in 'patient health monitors and trackers' (blood constituent levels) (as of Jan 2016)

\begin{tabular}{|c|c|c|c|c|}
\hline App name & OS & Description & $\begin{array}{l}\text { App } \\
\text { type }\end{array}$ & Hardware \\
\hline Calcium Pro & Android & $\begin{array}{l}\text { Tracks and monitors } \\
\text { the blood calcium, } \\
\text { vitamin D levels of } \\
\text { Patient for osteoporosis }\end{array}$ & Native & None \\
\hline $\begin{array}{l}\text { Glucose Buddy: } \\
\text { Diabetes Log }\end{array}$ & Android & $\begin{array}{l}\text { Manages Diabetes by } \\
\text { tracking glucose levels }\end{array}$ & Native & None \\
\hline Glucose Monitor & iOS & $\begin{array}{l}\text { Tracks glucose level } \\
\text { and weight }\end{array}$ & Native & None \\
\hline $\begin{array}{l}\text { Iron Tracker - } \\
\text { Hemochromatosis }\end{array}$ & Android & $\begin{array}{l}\text { Allows patients to track } \\
\text { and monitor their iron } \\
\text { levels }\end{array}$ & Native & None \\
\hline One Drop & iOS & $\begin{array}{l}\text { Manages Diabetes by } \\
\text { tracking glucose levels }\end{array}$ & Native & None \\
\hline
\end{tabular}

One example, the 'Cardiograph Heart Rate Monitor' (BIG DREAMS Lab 2014) app measures the user's heart rate via the placement of the index finger on the camera. Through the inbuilt camera flash, the app would then track the colour changes on the finger. There is also a significant move in this area towards peripheral devices, where there has been an increase in smart watches (built by major smartphone makers e.g. Apple, Samsung, etc., and other technology companies e.g. Fitbit) that monitors heart rate and send data to the smartphone.

\section{Blood pressure measurement [Table 13]}

Similar to measuring heart rate, measuring blood pressure is also another indicator of health status and condition. However unlike heart rate apps, the typical measurement of blood pressure would require the use of peripheral cuff devices connected to the smartphone. Nonetheless one app seems to be able to measure the parameter indirectly without the use of external devices. The 'Instant Blood Pressure' (Auralife 2014) relies on inbuilt camera and flash to provide blood pressure readings. As the technology is protected, it is likely that the dominant apps in this type would be more dependent on peripheral devices.

Table 9 Clinical apps classified in 'patient health monitors and trackers' (female menstrual cycle) (as of Jan 2016)

\begin{tabular}{|c|c|c|c|c|}
\hline $\begin{array}{l}\text { App } \\
\text { name }\end{array}$ & OS & Description & $\begin{array}{l}\text { App } \\
\text { type }\end{array}$ & Hardware \\
\hline Eva Diary & iOs & $\begin{array}{l}\text { Tracks patients' period cycles } \\
\text { and ovulation }\end{array}$ & Native & None \\
\hline $\begin{array}{l}\text { Period } \\
\text { Tracker }\end{array}$ & Android & $\begin{array}{l}\text { Helps keep track on menstrual } \\
\text { cycle }\end{array}$ & Native & None \\
\hline $\begin{array}{l}\text { iObstetrics } \\
\text { Pro }\end{array}$ & Android & $\begin{array}{l}\text { A tool to allow specialists to } \\
\text { monitor and synchronise the } \\
\text { progress of every patient's } \\
\text { pregnancy from their Pc, } \\
\text { SmartPhone or Tablet. }\end{array}$ & Hybrid & None \\
\hline
\end{tabular}

Table 10 Clinical apps classified in 'patient health monitors and trackers' (versatile health management) (as of Jan 2016)

\begin{tabular}{|c|c|c|c|c|}
\hline App name & OS & Description & $\begin{array}{l}\text { App } \\
\text { type }\end{array}$ & Hardware \\
\hline BloodPressureDB & $\begin{array}{l}\text { Android } \\
\& \mathrm{iOS}\end{array}$ & $\begin{array}{l}\text { Track, monitor and } \\
\text { store your blood } \\
\text { pressure along with } \\
\text { your pulse, blood } \\
\text { sugar and BMI }\end{array}$ & Hybrid & None \\
\hline BP Wiz & iOS & $\begin{array}{l}\text { Tracks Blood pressure, } \\
\text { weight and heart } \\
\text { health. It also tracks } \\
\text { medication }\end{array}$ & Native & None \\
\hline Diabetes Manager & iOS & $\begin{array}{l}\text { Tracks Blood glucose, } \\
\text { blood pressure, } \\
\text { weight and etc. }\end{array}$ & Native & None \\
\hline $\begin{array}{l}\text { Health Tracker \& } \\
\text { Manager }\end{array}$ & iOs & $\begin{array}{l}\text { Tracks blood glucose } \\
\text { and pressure levels }\end{array}$ & Native & None \\
\hline $\begin{array}{l}\text { Heart Wise Blood } \\
\text { Pressure Tracker }\end{array}$ & iOs & $\begin{array}{l}\text { Tracks Blood pressure, } \\
\text { weight and heart rate }\end{array}$ & Native & None \\
\hline $\begin{array}{l}\text { Qardio Heart } \\
\text { Health, Weight } \\
\text { and Blood } \\
\text { Pressure Monitor }\end{array}$ & iOs & $\begin{array}{l}\text { Tracks Blood pressure, } \\
\text { weight and heart } \\
\text { health }\end{array}$ & Native & None \\
\hline
\end{tabular}

\section{Eye diagnosis [Table 14]}

Apps in this category leverage on the camera/screen to allow for convenient and quick analysis and storage of eye images and tests. The 'Colour Blindness Test' (DaDo 2014) app tests for colour blindness and provides category of colour blindness in the result analysis. Another app such as 'Pain Eye' (Medina 2014) helps to investigate eye pain using captured images of the pupil using the smartphone's camera. Using clip-on peripheral camera adaptors, 'Peek Retina' (Peek 2015) was created by a team of eye specialists, software developers, designers and engineers for remote diagnosis. Many apps in this category leverage on the inbuilt

Table 11 Clinical apps classified in 'patient health monitors and trackers' (disease, pain and injury) (as of Jan 2016)

\begin{tabular}{|c|c|c|c|c|}
\hline App name & OS & Description & $\begin{array}{l}\text { App } \\
\text { type }\end{array}$ & Hardware \\
\hline FIND TB & Android & $\begin{array}{l}\text { Supports clinicians in } \\
\text { making decisions on the } \\
\text { diagnosis and treatment } \\
\text { of TB. }\end{array}$ & Native & Camera \\
\hline $\begin{array}{l}\text { Managing My } \\
\text { Hepatitis C }\end{array}$ & iOS & $\begin{array}{l}\text { Monitors patients' health } \\
\text { condition on Hepatitis }\end{array}$ & Native & None \\
\hline $\begin{array}{l}\text { Mobile } \\
\text { REMM }\end{array}$ & $\begin{array}{l}\text { Android } \\
\& \mathrm{iOS}\end{array}$ & $\begin{array}{l}\text { For clinical diagnosis and } \\
\text { treatment of radiation injury } \\
\text { during radiological and } \\
\text { nuclear emergencies. }\end{array}$ & Native & None \\
\hline $\begin{array}{l}\text { Pain } \\
\text { Stethoscope }\end{array}$ & Android & $\begin{array}{l}\text { Assess and graph patient- } \\
\text { reported outcomes of } \\
\text { chronic pain management } \\
\text { over time. }\end{array}$ & Native & None \\
\hline
\end{tabular}


Table 12 Clinical apps classified in 'heart rate measurement' (as of Jan 2016)

\begin{tabular}{|c|c|c|c|c|}
\hline App name & OS & Description & App type & Hardware \\
\hline Cardiometer ANT+ Heart Rate & Android & Measures and monitors heart rate & Native & $\begin{array}{l}\text { Heart rate Chest } \\
\text { Straps }\end{array}$ \\
\hline Cardiograph Heart Rate Monitor & Android \& iOS & Measures and monitors heart rate & Native & Camera with Flash \\
\hline Heart Beat Rate & Android & An application to measure heart rate & Native & Camera with Flash \\
\hline Heart Rate Plus LITE & iOS & Measures and monitors patients' heart rate & Native & Camera with Flash \\
\hline Heart Rate Monitor & Android & $\begin{array}{l}\text { Measures heart rate via placing your index finger on the } \\
\text { phone's camera len }\end{array}$ & Native & Camera with Flash \\
\hline Heart Rate Monitor Ant+ & Android & Measures and monitors heart rate & Native & $\begin{array}{l}\text { Heart rate Chest } \\
\text { Straps }\end{array}$ \\
\hline Medtimer & iOS & $\begin{array}{l}\text { Measure the time for each heart beat or breath to calculate } \\
\text { heart rate }\end{array}$ & Native & None \\
\hline iStethoscope Pro & iOS & Records heart beat and showing heart waveform for practioners. & Native & Camera with Flash \\
\hline Instant Heart Rate & Android \& iOS & $\begin{array}{l}\text { Measures heart rate via placing your index finger on the } \\
\text { phone's camera len }\end{array}$ & Native & Camera with Flash \\
\hline Runtastic Heart Rate Monitor & Android \& iOS & $\begin{array}{l}\text { Measures heart rate via placing your index finger on the } \\
\text { phone's camera len }\end{array}$ & Native & Camera with Flash \\
\hline What's My Heart Rate & Android \& iOS & $\begin{array}{l}\text { Measures the heart rate and breath rate through the lens of } \\
\text { the camera }\end{array}$ & Native & Camera \\
\hline
\end{tabular}

cameras in smartphones, and there is potential for these apps to even aid in detecting abnormalities when coupled with advanced image processing and artificial intelligent algorithms.

\section{Skin diagnosis [Table 15]}

Like the ophthalmology apps, skin diagnosis apps leverage on the smartphone inbuilt camera and image processing algorithms. Captured images of the skin are compared against a database of disease images. Apps such as 'Mole Doctor Skin Cancer App Dermatologist' (Teodorescu 2014) and 'Skin Analytics' (Skin Analytics Development 2014) enable the comparison of mole pictures against skin cancer images. These images can then be sent to dermatologists, making diagnosis more convenient. One limitation of such image based apps is that they are sensitive to the lighting and environmental factors during image capture. Such factors may severely affect the quality of the images and lead to poor diagnostic accuracies.

\section{Medical calculators [Tables 16 and 17]}

One frequent clinical mistake that can be fatal in medical treatment is the calculation of dosage. To prevent these mistakes, there are apps available to provide necessary medical calculations, conversions and chemical formulae checks. One such app, 'Calculate by QxMD' (QxMD Medical Software Inc 2015) app provides a number of unique calculators specific to various medical specialities and decision support tools including risk analysis. Another example, the Thyroid-SPOT (Sim et al. 2016) apps (Doctor and Patient versions) compute the homeostatic euthyroid set point, guiding the optimization of personalized treatment plans as well as to monitor the patient's condition. With these apps, more informed patients can also do their part and check their prescription or treatment regimen thus reducing clinical errors.

\section{Patient compliance [Table 18]}

As discussed earlier, patient compliance is a key factor in the success of treatment regimens. Considering also that most patients are willing to receive medication

Table 13 Clinical apps classified in 'blood pressure measurement' (as of Jan 2016)

\begin{tabular}{|c|c|c|c|c|}
\hline App name & OS & Description & App type & Hardware \\
\hline BP Calculator & Android & $\begin{array}{l}\text { Measures the blood pressure and keep record of blood pressure at } \\
\text { regular intervals. }\end{array}$ & Native & None \\
\hline ¡BP Blood Pressure & Android \& iOS & Blood pressure tracking and analysis tool. & Native & Blood Pressure scrap \\
\hline iHealth BPM & iOS & Measures blood pressure using a blood pressure dock. & Native & Blood Pressure Dock \\
\hline $\begin{array}{l}\text { Perf.Blood Pressure } \\
\text { (BP)Monitor }\end{array}$ & Android & $\begin{array}{l}\text { Calculates and measures your blood pressure via touching thumb on } \\
\text { the screen }\end{array}$ & Native & None \\
\hline
\end{tabular}


Table 14 Clinical apps classified in 'eye diagnosis' (as of Jan 2016)

\begin{tabular}{|c|c|c|c|c|}
\hline App name & OS & Description & App type & Hardware \\
\hline Anomaloscope & $\mathrm{iOS}$ & Tests for colour vision of patients & Native & None \\
\hline AmslerPro & iOS & Tests for abnormality in the foveal vision & Native & None \\
\hline Color Blindness Test & Android & Tests for colour blindness & Native & None \\
\hline Eye Care Plus - Eye Exercises & Android & Contains eye test to check visual acuity and information on eye health & Native & None \\
\hline Eye Diagnosis & Android & $\begin{array}{l}\text { Supports the visualization of eye photographs to help practitioners } \\
\text { diagnose eye diseases. }\end{array}$ & Native & Camera \\
\hline $\begin{array}{l}\text { Eye test } \\
\text { Eye Test Charts } \\
\text { Full Visual Test } \\
\text { Vision Test } 2.0\end{array}$ & $\begin{array}{l}\text { Android } \\
\text { Android } \\
\text { Android } \\
\text { Android }\end{array}$ & $\begin{array}{l}\text { Contains many eye tests including Visual acuity test } \\
\text { Tests for visual acuity } \\
\text { Tests for visual acuity } \\
\text { Tests for visual acuity }\end{array}$ & Native & None \\
\hline Morphision & iOS & Qualifies the symptom of distortion in their patient's eyes & Native & None \\
\hline Pain Eye & iOS & Takes pictures of eyes to diagnose eye pains & Native & Camera \\
\hline TeleMed & Android & $\begin{array}{l}\text { An application that connects to healthcare services and allows sending } \\
\text { photos of eye as part of medical teleconsultation. }\end{array}$ & Hybrid & None \\
\hline Visual Acuity Test & Android & Monitor acuteness and clearness of vision in person's eyes & Native & None \\
\hline Vision Test & Android & Includes visual acuity test & Native & None \\
\hline
\end{tabular}

reminders (Kebede, et al. 2015) and likely to possess smartphones, medication reminder apps can improve compliance. One such example, 'Medisafe Meds \& Pill Reminder' (MediSafe ${ }^{\mathrm{TM}}$ 2016) monitors and has reminders for scheduled medication times. Such apps are particularly useful for the elderly and those with multiple treatment regimens concurrently.

\section{Discussion}

With the smartphone becoming increasingly versatile in different fields of work, there is great promise for its role in the future of personalized medicine. In the current survey of the available apps in the largest apps stores: Google and Apple, we surveyed relevant apps that benefit both clinicians and patients. While there are many apps within the various medical specialities that may exist, they were not covered as focus is given to areas where patients can play a role, such as taking pictures (skin/eye) for better monitoring and diagnosis. Obviously, certain levels of technical savviness and acceptance from the users (both patient and clinicians) are necessary for the desired benefits of using these apps. The apps surveyed in this review focus on the many clinical aspects with the end-goal of improving the efficiency, cost, simplicity and effectiveness of healthcare. While a horde of apps exist, the majority found in Google and Apple app stores are either glossaries of clinical information apps for health professionals, or basic health knowledge apps for the layman. Even amongst the numerous apps designed for clinical data management and monitoring health, only a minority were found to be of direct practical use. In fact, focussing on the directly practical apps, there is a paucity of evidence-based or professional-informed apps (Majeed-

Table 15 Clinical apps classified in 'skin diagnosis' (as of Jan 2016)

\begin{tabular}{lll}
\hline App name & OS & Description \\
\hline Doctor Mole - Skin Cancer App & $\begin{array}{l}\text { Android } \\
\text { iOS }\end{array}$ & Automatic analysis of mole images to diagnose skin cancer. \\
Mole Checker & iOS & Takes pictures of skin moles and keep track of changes \\
Skin Analytics & Android & Takes photos of skin moles and compares for diagnosis of skin cancer \\
Skin Cancer App - MySkinPal & Android & Takes photos of skin moles and compares for diagnosis of skin cancer \\
SkinVision - Melanoma app & Android & Takes photos of skin moles and compares for diagnosis of skin cancer \\
Skin MD Now - Expert Skin Help & Android & Send skin photos to Dermatologists for quick diagnosis. \\
Skin Scanner & Android & Takes photos of skin moles for analysis for skin cancer \\
SpotMole & Android & Scans photos of skin moles to detect for melanoma \\
iDoc24 - Dermatologist Online & Android \& iOS & $\begin{array}{l}\text { Sends on-demand dermatologist skin photos for diagnosis } \\
\text { and monitoring. }\end{array} \quad$ Camera \\
\hline
\end{tabular}


Table 16 Clinical apps classified in 'medical calculators' (calculations) (as of Jan 2016)

\begin{tabular}{|c|c|c|c|c|}
\hline App name & OS & Description & $\begin{array}{l}\text { App } \\
\text { type }\end{array}$ & Hardware \\
\hline ACC Guideline Clinical App & Android & Contains interactive tools such as risk scores, dosing calculators, and algorithms. & Native & None \\
\hline BODE Calculator & Android & Calculates the COPD levels to treat lung diseases. & Native & None \\
\hline Calculate by QxMD & Android & Includes tools for calculations used in clinical practice. & Native & None \\
\hline $\begin{array}{l}\text { CuidApp - Nurses and } \\
\text { Doctors }\end{array}$ & Android & Includes calculators and unit conversions. & Native & None \\
\hline CKD Risk Calc Pro & iOS & Evaluates Chronic Kidney Disease via calculations & Native & None \\
\hline Digoxin Calculator & Android & Estimates a patient's digoxin requirements for the treatment of heart failure. & Native & None \\
\hline Ezabx & Android & Contains a metric converter and references for common microbes and antibiotics. & Native & None \\
\hline $\begin{array}{l}\text { GRACE } 2.0 \text { ACS Risk } \\
\text { Calculator }\end{array}$ & Android & Calculates the probability of fatality after an acute coronary syndrome. & Native & None \\
\hline GFR \& BSA Calculator & Android & Estimates the expected Glomerular filtration rate of patients & Native & None \\
\hline Haemoscore & Android & $\begin{array}{l}\text { Includes score calculators \& algorithms to facilitate decision making in both } \\
\text { diagnosis and treatment of thrombotic and bleeding problems. }\end{array}$ & Native & None \\
\hline MedCalc 3000 Cardiac & Android & $\begin{array}{l}\text { Provides medical equations, clinical calculator and dose/unit converters used by } \\
\text { Cardiovascular specialists }\end{array}$ & Native & None \\
\hline $\begin{array}{l}\text { Medical Calculators \& } \\
\text { Equation }\end{array}$ & Android & Contains a wide range of calculators/convertors for medical purposes. & Native & None \\
\hline Medical Formulas & $\begin{array}{l}\text { Android \& } \\
\text { iSO }\end{array}$ & $\begin{array}{l}\text { Medical Calculator that access to main equations, formula and scores used in } \\
\text { clinical practice. }\end{array}$ & Native & None \\
\hline Medical Tools & Android & Medical calculators, interpretation and scoring systems. & Native & None \\
\hline $\begin{array}{l}\text { Melanoma Visual Risk } \\
\text { Calculator }\end{array}$ & iOS & Calculates the possibility of a mole being a malignant melanoma & Native & Camera \\
\hline Opioid Converter & Android & Application designed to aid with opioid dose conversions. & Native & None \\
\hline $\begin{array}{l}\text { Ovulation calculator \& fertility } \\
\text { tracker }\end{array}$ & iOS & Calculates ovulation cycle and tracks fertility rate & Native & None \\
\hline Pedia BP & iOS & Blood pressure calculator & Native & None \\
\hline Pregnancy Calculator & Android & Estimates the expected due date for the born of a baby. & Native & None \\
\hline $\begin{array}{l}\text { Throid-SPOT (Dr and Patient } \\
\text { versions) }\end{array}$ & $\begin{array}{l}\text { Android and } \\
\text { iOS }\end{array}$ & Calculates homeostatic euthryroid set points in thyroid diseases & Native & None \\
\hline
\end{tabular}

Ariss, et al. 2015; Krebs and Duncan 2015; Subhi et al. 2015). One contributing factor for the dearth of apps in certain medical specialties is that certain diagnostic or monitoring procedures may be dependent on peripheral devices (see example of blood pressure and Peek Retina above). Such demands of peripheral devices thus limit the exploitation of smartphones. Other factors include the administration and certification required of medical devices which would vary between countries, and also for the device type. As there are a large number of smartphone models and makers, the in-built sensors in these phones would vary. This results in significant inter-equipment errors that may prevent any standardized guidelines or procedures required for professional clinical use. These make certification and use of smartphone as medical devices more challenging and unlikely to be approved by various authorities (scope of this is beyond this article due to the varying requirements). In the event they are approved for use, it is likely that many of these smartphone-dependent devices will require skilled personnel. As a result, clinical apps will mostly play a supportive role rather than as direct medical equipment replacements. Such limitations may be slightly mitigated by standardised peripheral devices, but

Table 17 Clinical apps classified in 'medical calculators' (checkers) (as of Jan 2016)

\begin{tabular}{|c|c|c|c|c|}
\hline App name & OS & Description & App type & Hardware \\
\hline Drugs.com Medication Guide & Android & $\begin{array}{l}\text { Provides drug information, identify pills, check interactions and set up personal } \\
\text { medication records for Health professionals. }\end{array}$ & Native & None \\
\hline WebMD & Android & Includes decision-support tools such as WebMD's Symptom Checker. & Native & None \\
\hline
\end{tabular}


Table 18 Clinical apps classified in 'patient compliance' (as of Jan 2016)

\begin{tabular}{|c|c|c|c|c|}
\hline App name & OS & Description & App type & Hardware \\
\hline Medisafe Meds \& Pill Reminder & Android & $\begin{array}{l}\text { Add medications, get reminders for taking pills and receive constant } \\
\text { tracking of your health progress. }\end{array}$ & Native & None \\
\hline Medica Reminders & iOS & $\begin{array}{l}\text { Adds medications, get reminders for taking pills and receive constant } \\
\text { tracking of your health progress. }\end{array}$ & Native & None \\
\hline Pill Alert & iOS & & & \\
\hline MyPill & iOS & Birth control pill reminder & Native & None \\
\hline Pill Reminder & iOS & Reminds patients to take medicine, contraceptive and other medication & Native & None \\
\hline Pill Monitor Free & iOS & Medication reminder & Native & None \\
\hline
\end{tabular}

these peripheral devices have their own limitations in accessibility to the general public.

Nonetheless in societies with less stringent medical regulation and where specialized medical equipment may not be readily available, the smartphone certainly has a role not only as a patient companion, but also as a screening tool for health problems. The smartphone has already been shown to aid in numerous areas: patient monitoring, transmission of clinical data between patients and clinicians, encouraging patient compliance, and helping with clinical calculations and decision making. Certainly the patient now has the resources to take better ownership of their own health with such apps (regulatory board approved or not) at their disposal.

\section{Conclusion}

With an obvious role in personalized healthcare, the smartphone promises to be a portable medical toolkit/ clinical gathering device for both clinicians and patients. Much remains to be done with much more apps and peripheral devices that can be made, but with the collaborative effort between medical specialists, software developers and hardware engineers, the future of the smartphone medical toolkit can be materialized. The days of convenient house-visits might return in the form of app consultations.

\section{Competing interests}

The authors declare no competing interests.

\section{Authors' contributions}

CK and YX drafted the manuscript. PV made the tables. SKEG directed and edited the writing of the manuscript. All authors have read and approve of the final manuscript.

Received: 18 February 2016 Accepted: 6 June 2016

Published online: 19 July 2016

\section{References}

AuraLife. instant Blood Pressure. 2014 [Online] Available at: http://www. instantbloodpressure.com. [Accessed 31 Oct 2015].

BIG DREAMS Lab. Cardiograph Heart Rate Monitor. 2014 [Online] Available at: https://play.google.com/store/apps/details?id=com.bigdreams. cardiographheartbeat. [Accessed 31 Oct 2015].

Cocoalena Software. PulsePRO - Free AF Detector \& Heart Rate Monitor. 2015 [Online] Available at: https://itunes.apple.com/sg/app/pulsepro-free-afdetector/id973258103?mt=8. [Accessed 31 Aug 2015].
DaDo. Color Blindness Test. 2014 [Online] Available at: https://play.google.com/ store/apps/details?id=com.hieuit.colorblindtest\&hl=en. [Accessed 31 Oct 2015].

Evgeny C. My Patients. 2015 [Online] Available at: https://play.google.com/store/ apps/details?id=com.drchernj.patientlist. [Accessed 31 Dec 2015].

FRUCT. Blood Pressure Diary. 2016 [Online] Available at: https://play.google.com/store/ apps/details?id=org.fruct.yar.bloodpressurediary\&hl=en. [Accessed 14 Feb 2016].

Gan SKE, Loh CY, Seet B. Hypertension in young adults-an under-estimatedproblem. Singap Med J. 2003;44:448-52.

Higgins JP. Smartphone applications for Patients' health \& fitness. Am J Med. 2015;9343(15):00537-9. doi:10.1016/j.amimed.2015.05.038 [Epub ahead of print].

Inc, H. Healthjump. 2015 [Online] Available at: https://itunes.apple.com/sg/app/ healthjump/id864038041?mt=8. [Accessed 31 Oct 2015].

Kebede M, Zeleke A, Asemahagn M, Fritz F. Willingness to receive text message medication reminders among patients on antiretroviral treatment in North West Ethiopia: a cross-sectional study. BMC Medical Informatics and Decision Making. 2015;15:65.

Krebs P, Duncan D. Health App use among US mobile phone owners: a national survey. JMIR mHealth and uHealth. 2015;3(4):e101.

Majeed-Ariss R et al. Apps and adolescents: a systematic review of Adolescents' use of mobile phone and tablet apps that support personal management of their chronic or long-term physical conditions. Journal of Medical Internet Research. 2015;17(12):e287.

Martin $L$ et al. The challenge of patient adherence. Therapeutics and Clinical Risk Management. 2005;1(3):189-99.

Medina J. Pain Eye. 2014 [Online] Available at: https://itunes.apple.com/sg/app/ pain-eye/id828047478? $\mathrm{mt}=8$. [Accessed 31 Oct 2015].

MediSafe ${ }^{\mathrm{TM}}$. MediSafe Meds \& Pill Reminder. 2016 [Online] Available at: https:// play.google.com/store/apps/details?id=com.medisafe.android.client. [Accessed 13 Feb 2016].

Peek. Professional eye exams from your smartphone. 2015 [Online]. Available at http://www.peekvision.org/[Accessed 1 Mar 2016].

QxMD Medical Software Inc. Calculate by QxMD. 2015 [Online] Available at: https://play.google.com/store/apps/details?id=com.qxmd.calculate\&hl=en. [Accessed 1 Dec 2015].

Sim JZ, Nguyen PV, Gan SKE, Leow MKS (2015) Thyroid-SPOT for Android and iOS. Invention disclosure filed May 2015 SICS/Z/09136, ETPL A*STAR.

Siyami Apps L. Patient Records Doctor ON GO-T. 2015 [Online] Available at: https:// play.google.com/store/apps/details?id=com.siyami.apps.patientregister. [Accessed 31 Dec 2015].

Skin Analytics Development. Skin Analytics. 2014 [Online] Available at: https:// play.google.com/store/apps/details?id=com.skinanalytics.skinuploader\&hl=en. [Accessed 31 October 2015].

Subhi $Y$ et al. Expert involvement and adherence to medical evidence in medical mobile phone apps: a systematic review. JMIR Mhealth Uhealth. 2015;3(3):e79.

Teodorescu P. Mole Doctor Skin Cancer App Dermatologist. 2014 [Online] Available at: https://itunes.apple.com/us/app/mole-doctor-skin-cancer-app/ id887805384? $\mathrm{mt}=8$. [Accessed 31 Oct 2015]. 